\title{
Facile Purification of Honokiol and its Antiviral and Cytotoxic Properties
}

\author{
Franck Amblard ${ }^{\dagger}, \ddagger$, David Delinsky ${ }^{\ddagger}$, Jack L. Arbiser ${ }^{\dagger}$, and Raymond F. Schinazi ${ }^{*}, \dagger, \ddagger$ \\ Department of Pediatrics and Dermatology, Emory University School of Medicine, Atlanta, GA \\ 30322, and Veterans Affairs Medical Center, Decatur, GA 30033 \\ †Emory University School of Medicine \\ ‡Veterans Affairs Medical Center
}

\begin{abstract}
A separation of honokiol 1 from the closely structurally related magnolol $\mathbf{2}$ was developed.

Honokiol demonstrated weak activity against HIV-1 in human lymphocytes.
\end{abstract}

\begin{abstract}
Simple biphenyl neolignans, honokiol 1 and magnolol $\mathbf{2}$ are the main constituents of the stem bark of Magnolia abovata thumb and Magnolia officinalis rhed, which have been used as a traditional Chinese medicine for thousands of years for treatment of anxiety and stroke. These natural products are also reported to have various biological activities including antioxidative and antidepressant properties ${ }^{1,2}$ They inhibit intracellular calcium mobilization in platelets $^{3}$, relax vascular smooth muscles by inhibiting calcium influx through voltage-gated calcium channels. ${ }^{4}$ Moreover, recent studies in our laboratory indicated that honokiol induced apoptosis in tumor cells and inhibited angiogenesis through blocking phosphorylation of vascular endothelial growth factor receptor 2 (VEGFR 2). ${ }^{5}$ Honokiol also exhibited a direct antitumor activity through tumor necrosis factor apoptosis-inducing ligand (TRAIL/Apo2L) signaling. ${ }^{5}$ Thus, the combination of both anti-angiogenic and antitumor activities distinguishes honokiol from many other natural products. Because of their important biological properties, large quantities of pure materials were needed for further preclinical and clinical studies. However, syntheses of pure honokiol and magnolol are not very efficient, requiring multisteps strategies with low to good global yields. ${ }^{6}$ Currently, the extraction of honokiol is achieved from magnolia trees, but always as a mixture with magnolol. Because of the structural resemblance, these two compounds are difficult to separate by conventional thin layer chromatography or column chromatography; the purification requiring either use of special chromatographic conditions or electromigration ${ }^{7}$ adding significantly to the cost of preparing honokiol or magnolol and are thus not readily adaptable to large scale.
\end{abstract}

Honokiol differs from magnolol only on the position of a hydroxyl group, but in the case of magnolol, the hydroxyl groups appear like a protectable diol. This spacial arrangement provided an opportunity for a selective chemical modification allowing a facile separation.

The reaction of a mixture of $\mathbf{1}$ and $\mathbf{2}$ with 2,2-dimethoxypropane under catalytic acidic conditions readily resulted in the selective formation of $\mathbf{3}$; whereas honokiol was unchanged under these conditions, since both hydroxyl groups are spatially too far to be protected. The

\footnotetext{
*To whom correspondence should be addressed. Tel: (404) 728-7711. Fax: (404) 728-7726. rschina@emory.edu. .

Supporting Information Available: HPLC and NMR data of compounds, characterization and evaluation of their purity. This material is available free of charge via Internet at http://pubs.acs.org.
} 
resulting mixture of $\mathbf{1}$ and $\mathbf{3}$ could be readily separated by simple and economical flash chromatography on silica gel giving honokiol in good yield with $96.8 \%$ purity as determined by HPLC. The purity of honokiol can be raised to $99.8 \%$ by repeating the reaction under the same conditions on the partially purified honokiol. Finally, deprotection of $\mathbf{3}$ under acidic condition affords highly pure (99.8\%) magnolol in good yield with no detectable honokiol as determined by HPLC.

Purified honokiol and magnolol were evaluated for their cytotoxicity in normal and cancer cells. Both compounds demonstrate moderate cytotoxicity in a human peripheral blood mononuclear (PBM) cells, African green monkey kidney (Vero) cells and human T-cell lymphoma (CEM) cells. The median cytotoxic concentration $\left(\mathrm{CC}_{50}\right)$ in these cells were respectively 16.1, 22.5, $10.9 \mu \mathrm{M}$ for honokiol and 38.6, 50.6, $99.5 \mu \mathrm{M}$ for magnolol. Honokiol and magnolol were also evaluated against HIV-1 in human PBM cells and found to have a median effective concentration $\left(\mathrm{EC}_{50}\right)$ of 3.3 and $69.3 \mu \mathrm{M}$ respectively. Thus the selectivity index of honokiol was approximately five (The selectivity index is generally defined as the ratio between $\mathrm{CC}_{50}$ and $\mathrm{EC}_{50}$ values). The antiviral ${ }^{8}$ and cytotoxicity ${ }^{9}$ assays were performed as previously described.

This work provides a simple and economical method for the separation of $\mathbf{1}$ and $\mathbf{2}$. Whereas our method produced honokiol in one step in a $91 \%$ yield, two previously published syntheses were completed in three ${ }^{6 a}$ to nine ${ }^{6 b}$ steps with yields of 15 and $26 \%$.

\section{Experimental Section}

Commercially available chemicals and solvents were reagent grade and used as received except $p$-TSA which was coevaporated with toluene prior to use. Extracts of a mixture of honokiol and magnolol (58/33) obtained from magnolia trees was purchased from Conba Pharmaceutical (Zhejiang, China). The reactions were monitored by thin-layer chromatography (TLC) analysis using silica gel plates (Kieselgel $60 \mathrm{~F}_{254}$, E. Merck). Compounds were visualized by UV irradiation and/or spraying with $20 \% \mathrm{H}_{2} \mathrm{SO}_{4}$ in EtOH, followed by charring at $150{ }^{\circ} \mathrm{C}$. Column chromatography was performed on silica gel $60 \mathrm{M}$ (0.040-0.063 mm, E. Merck). ${ }^{1} \mathrm{H}$ and ${ }^{13} \mathrm{C}$ NMR spectra were recorded on a Mercury 300 spectrometer at $300 \mathrm{MHz}$ for ${ }^{1} \mathrm{H}$ and $75 \mathrm{MHz}$ for ${ }^{13} \mathrm{C}$, respectively, using internal $\mathrm{CHCl}_{3}$ as reference (7.26 ppm for ${ }^{1} \mathrm{H}$ and $77.23 \mathrm{ppm}$ for ${ }^{13} \mathrm{C}$ ); signals are reported as s (singlet), $\mathrm{d}$ (doublet), t (triplet), q (quartet), and $\mathrm{m}$ (multiplet). High Resolution Mass spectra (HRMS) were performed by the Mass Spectrometry Center of Emory University. The nomenclature used for the compounds reported in this paper is in accordance with the IUPAC rules.

\section{Protection of magnolol in a mixture of honokiol and magnolol}

A solution of a mixture of honokiol and magnolol (58:33 as determined by HPLC, $8 \mathrm{~g}$ ) in 2,2-dimethoxypropane $(48 \mathrm{~mL}$ ) was stirred overnight in presence of a catalytic amount of $p$ TSA. After neutralization of the solution with $\mathrm{NaHCO}_{3}$, the mixture was diluted with EtOAc (150 mL) and washed with $\mathrm{H}_{2} \mathrm{O}$ and brine then the organic layer was dried over $\mathrm{MgSO}_{4}$, filtered and evaporated. The crude product was separated by flash chromatography on silica gel (hexane:EtOAc, 85:15) to give protected magnolol 3 (2.8 g) and honokiol 1 (4.64 g).

\section{5,5'-Diallyl-[1,1'-biphenyl]-2,2'-dimethylacetal 3}

(Protected magnolol): ${ }^{1} \mathrm{H}-\mathrm{NMR}\left(\mathrm{CDCl}_{3}\right) \delta 1.64\left(\mathrm{~s}, 6 \mathrm{H}, \mathrm{CH}_{3} \times 2\right), 3.44(\mathrm{~d}, 4 \mathrm{H}, J=6.6 \mathrm{~Hz}$, $\left.\mathrm{CH}_{2} \times 2\right), 5.08-5.15\left(\mathrm{~m}, 4 \mathrm{H}, \mathrm{CH}_{2} \times 2\right), 5.81-6.12(\mathrm{~m}, 2 \mathrm{H}, \mathrm{CH} \times 2), 7.02(\mathrm{~d}, 2 \mathrm{H}, J=8 \mathrm{~Hz}$, $\left.\mathrm{CH}_{\mathrm{ar}} \times 2\right), 7.14\left(\mathrm{dd}, 2 \mathrm{H}, J=1.8,8 \mathrm{~Hz}, \mathrm{CH}_{\mathrm{ar}} \times 2\right), 7.31\left(\mathrm{~d}, 2 \mathrm{H}, J=1.8 \mathrm{~Hz}, \mathrm{CH}_{\mathrm{ar}} \times 2\right) ;{ }^{13} \mathrm{C}-$ NMR $\left(\mathrm{CDCl}_{3}\right) \delta 25.3,40.0,115.4,116.1,123.3,128.4,128.8,133.2,136.8,137.5,150.1$. HRMS: $\mathrm{C}_{21} \mathrm{H}_{23} \mathrm{O}_{2}\left[\mathrm{M}+\mathrm{H}^{+}\right]$, calcd m/z 307.16926, found $\mathrm{m} / \mathrm{z}$ 307.16925. 


\section{Preparation of magnolol from 3}

A solution of protected magnolol $3(2.8 \mathrm{~g})$ in $\mathrm{MeOH}(75 \mathrm{~mL})$ and $1 \mathrm{M} \mathrm{HCl}(1 \mathrm{~mL})$ was heated under reflux overnight. After evaporation of the solvent, the crude compound was diluted in EtOAc $(100 \mathrm{~mL})$ and washed with $\mathrm{H}_{2} \mathrm{O}$ and brine. The organiclayer was then dried with $\mathrm{MgSO}_{4}$ and concentrated in vacuo. The crude product was purified by flash chromatography on silica gel (hexane: EtOAc, $85: 15)$ to give magnolol 3 (2.3 g) in 95\% yield.

\section{Supplementary Material}

Refer to Web version on PubMed Central for supplementary material.

\section{Acknowledgments}

We acknowledge the use of Shared Instrumentation provided by grants from the National Institutes of Health (NIH) and the NSF. RFS is supported by the Emory University Center for AIDS Research, by the Department of Veterans Affairs and the NIH (grant RO-AI-32351). JLA is supported by the NIH (grant AR 02030).

\section{References}

(1). Lo YC, Teng CM, Chen CF, Chen CC, Hong CY. Magnolol and honokiol isolated from Magnolia officinalis protect rat heart mitochondria against lipid peroxidation. Biochem. Pharmacol. 1994; 47:549-553. [PubMed: 8117323]

(2). Nakazawa T, Yasuda T, Ohsawa K. Metabolites of orally administered Magnolia officinalis extract in rats and man and its antidepressant-like effects in mice. J. Pharm Pharmacol. 2003; 55:1583-1591. [PubMed: 14713371]

(3). Teng CM, Chen CC, Ko FN, Lee LG, Huang TF, Chen YP, Hsu HY. Two antiplatelet agents from Magnolia officinalis. Thromb. Res. 1988; 50:757-765. [PubMed: 3413728]

(4). Teng CM, Yu SM, Chen CC, Huang YL, Huang TF. EDRF-release and Ca+(+)-channel blockade by magnolol, an antiplatelet agent isolated from Chinese herb Magnolia officinalis, in rat thoracic aorta. Life Sci. 1990; 47:1153-1161. [PubMed: 2172682]

(5). Bai X, Cerimele F, Ushio-Fukai M, Waqas M, Campbell PM, Govindarajan B, Der CJ, Battle T, Frank DA, Ye K, Murad E, Dubiel W, Soff G, Arbiser JL. Honokiol, a small molecular weight natural product, inhibits angiogenesis in vitro and tumor growth in vivo. J. Biol. Chem. 2003; 278:35501-3557. [PubMed: 12816951]

(6)(a). Takeya T, Okubo T, Tobinaga S. Synthesis of unsymmetrical biphenyl lignans, honokiol and related coumpounds, utilizing quinol-acetates as reactive intermediates. Chem. Pharm. Bull. 1986; 34:2066-2075.(b) Esumi T, Makado G, Zhai H, Shimizu Y, Mitsumoto Y, Fukuyama Y. Efficient synthesis and structure-activity relationship of honokiol, a neurotrophic biphenyl-type neolignan. Bioorg. Med. Chem. Lett. 2004; 14:2621-2625. [PubMed: 15109665] (c) Gu W, She X, Pan X, Yang T-K. Enantioselective syntheses of $(S)$ - and (R)-8,9-dihydroxydihydromagnolol. Tetrahedron: Asymmetry. 1998; 9:1377-1380.

(7)(a). For a recent review see : Slanina J, Glatz Z. Separation procedures applicable to lignan analysis. J. Chromatogr. B. 2004; 812:215-229. (b) Wang X, Wang Y, Geng Y, Li F, Zheng C. Isolation and purification of honokiol and magnolol from cortex Magnoliae officinalis by high-speed counter-current chromatography. J. Chromatogr. A. 2004; 1036:171-175. [PubMed: 15146918]

(8). Schinazi RF, Sommadossi JP, Saalman V, Cannon DL, Xie M-W, Hart GC, Hahn EF. Activities of 3'-azido-3'-deoxythymidine nucleotide dimers in primary lymphocytes infected with human immunodeficiency virus type 1. Antimicrob. Agents Chemother. 1990; 34:1061-1067. [PubMed: 2393266]

(9). Stuyver LJ, Lostia S, Adams M, Mathew J, Pai BS, Grier J, Tharnish P, Choi Y, Chong Y, Choo H, Chu CK, Otto MJ, Schinazi RF. Antiviral activities and cellular toxicities of modified 2', 3'dideoxy-2',3'-didehydrocytidine analogues. Antimicrob. Agents Chemother. 2002; 46:38543860. [PubMed: 12435688] 


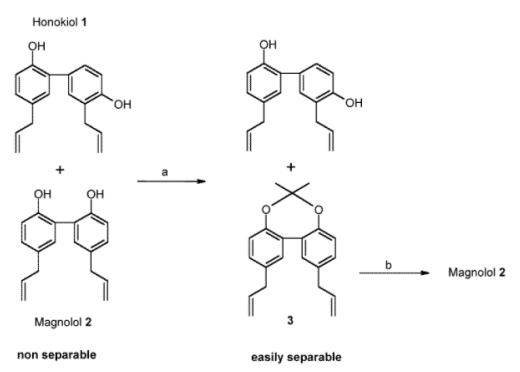

Scheme 1.

a) 2,2-dimethoxypropane, $p$-toluene sulfonic acid, rt; b) $\mathrm{MeOH}, 1 \mathrm{M} \mathrm{HCl}$, reflux 